\title{
How old is the ice beneath Dome A, Antarctica?
}

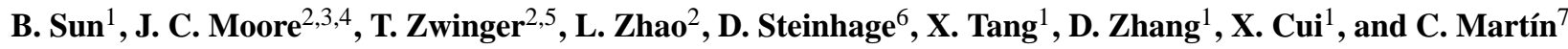 \\ ${ }^{1}$ Polar Research Institute of China, Shanghai 200129, China \\ ${ }^{2}$ College of Global Change and Earth System Science, Beijing Normal University, Beijing, China \\ ${ }^{3}$ Arctic Centre, University of Lapland, P.O. Box 122, 96101 Rovaniemi, Finland \\ ${ }^{4}$ Department of Earth Sciences, Uppsala University, Villavägen 16, Uppsala, 75236, Sweden \\ ${ }^{5} \mathrm{CSC}$-IT Center for Science Ltd., Espoo, Finland \\ ${ }^{6}$ Alfred Wegener Institute Helmholtz Centre for Polar and Marine Research, Bremerhaven, Germany \\ ${ }^{7}$ British Antarctic Survey, Natural Environment Research Council, Cambridge, UK \\ Correspondence to: J. C. Moore (john.moore.bnu@gmail.com)
}

Received: 13 December 2013 - Published in The Cryosphere Discuss.: 13 January 2014

Revised: 19 May 2014 - Accepted: 21 May 2014 - Published: 27 June 2014

\begin{abstract}
Chinese scientists will start to drill a deep ice core at Kunlun station near Dome A in the near future. Recent work has predicted that Dome A is a location where ice older than 1 million years can be found. We model flow, temperature and the age of the ice by applying a three-dimensional, thermomechanically coupled full-Stokes model to a $70 \times 70 \mathrm{~km}^{2}$ domain around Kunlun station, using isotropic non-linear rheology and different prescribed anisotropic ice fabrics that vary the evolution from isotropic to single maximum at $1 / 3$ or $2 / 3$ depths. The variation in fabric is about as important as the uncertainties in geothermal heat flux in determining the vertical advection which in consequence controls both the basal temperature and the age profile. We find strongly variable basal ages across the domain since the ice varies greatly in thickness, and any basal melting effectively removes very old ice in the deepest parts of the subglacial valleys. Comparison with dated radar isochrones in the upper one third of the ice sheet cannot sufficiently constrain the age of the deeper ice, with uncertainties as large as 500000 years in the basal age. We also assess basal age and thermal state sensitivities to geothermal heat flux and surface conditions. Despite expectations of modest changes in surface height over a glacial cycle at Dome A, even small variations in the evolution of surface conditions cause large variation in basal conditions, which is consistent with basal accretion features seen in radar surveys.
\end{abstract}

\section{Introduction}

The search for ice older than 1.5 million years is an active and key question for the Quaternary science community (e.g. Severinghaus, 2010; Van Liefferinge and Pattyn, 2013). The Gamburtsev subglacial mountains beneath Dome A were a major centre of ice-sheet nucleation during the Cenozoic (DeConto and Pollard, 2003; Sun et al., 2009), and hence potentially can provide ancient ice for paleoclimatic research. Kunlun station $\left(80^{\circ} 25^{\prime} 01^{\prime \prime} \mathrm{S}, 77^{\circ} 06^{\prime} 58^{\prime \prime} \mathrm{E}, 4092 \mathrm{~m}\right.$ a.s.l. $)$ is located where the thickest ice $(3090 \mathrm{~m})$ occurs on the gently sloping summit region of Dome A (Fig. 1). Preliminary investigation has shown that the annual mean temperature (measured at $10 \mathrm{~m}$ below the surface) at Dome A is $-58.5^{\circ} \mathrm{C}$, the lowest annual mean temperature ever recorded on the surface of the earth (Hou et al., 2007). The average snow accumulation rate during the past several centuries (AD 12602004) is about $25 \mathrm{~mm}$ ice equivalent $\mathrm{yr}^{-1}$ (Jiang et al., 2012), which is typical of other sites in the East Antarctic interior (e.g. Ritz et al., 2001).

In stark contrast with the nearly flat surface topography, radar mapping suggests that the Gamburtsev Mountains are very rugged alpine-style terrain (Bell et al., 2011; Fig. 1). This produces complex ice flow which, in some places, may cause mixing of basal ice layers or localized basal melting and refreezing. When considering locations for deep ice coring in search of very ancient ice, ice thickness and geothermal heat flux has been recognized as of crucial importance. Modelling these parameters, Van Liefferinge and 

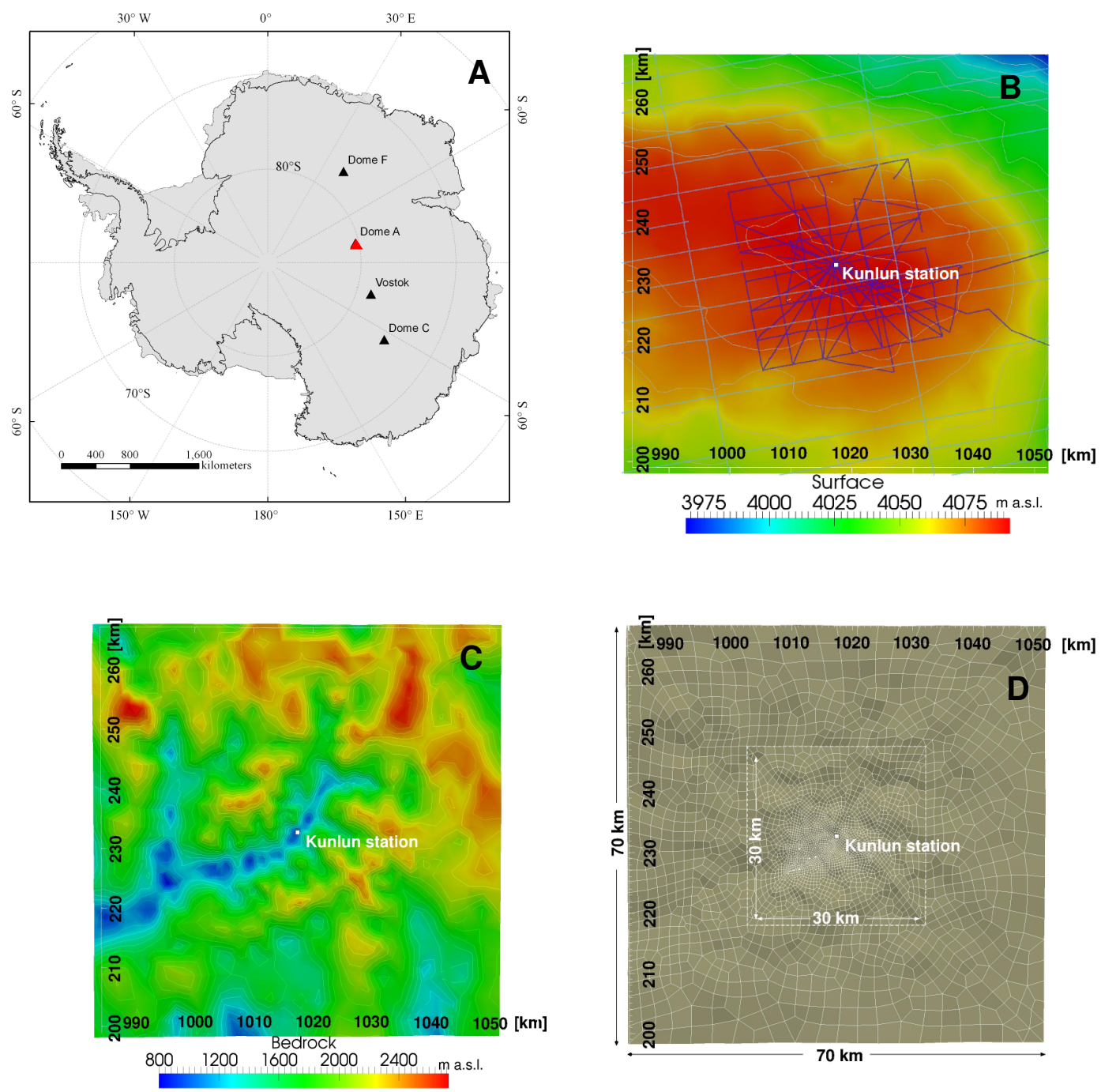

Figure 1. (A) Map of Antarctica with locations of Dome A, Dome C, Dome F and Vostok; (B) surface topography in the vicinity of Dome A and Kunlun station (contour spacing $10 \mathrm{~m}$ ), black lines show ground-based radar surveys, grey lines are airborne radar lines; (C) bedrock topography (contour spacing $200 \mathrm{~m}$ ); and (D) the finite element mesh in the $70 \times 70 \mathrm{~km}^{2}$ domain, with higher resolution in the central $30 \times 30 \mathrm{~km}^{2}$ region. The coordinate system is WGS 1984 plotted using Antarctic Polar Stereographic with standard parallel at $71^{\circ} \mathrm{S}$ and central meridian at $0^{\circ} \mathrm{E}$.

Pattyn (2013) suggest that the best locations to search would not be where the ice is thickest, but where heat flux is low and ice thickness less than $3 \mathrm{~km}$. This is because ice is a good thermal insulator and in combination with sufficient basal heat flux leads to basal melting and loss of old ice at the bed. Hence, in some places, there will be deep layers of relatively young ice compared with locations where thinner ice is frozen to the bed. These models rely on assumptions of isotropic ice and make use of Glen's flow law, whereas observations suggest that strong anisotropic fabric is commonplace in Antarctica (Fujita et al., 1999; Durand et al., 2009). While anisotropy will not strongly change the temperature profile in the ice, it affects the vertical velocity profile with depth, and that will influence the age at any depth, especially in deeper layers. However, thick ice will generally produce warmer basal temperatures than thin ice, and anisotropy does not greatly affect basal temperature or locations where melting will occur (Seddik et al., 2011).

Ice is a strongly anisotropic medium, and deep ice cores typically show that the initially random orientation of ice grains alters as the ice is buried and subjected to strain, leading to preferential orientation of the crystal $c$ axis (Shoji and Langway, 1985; Wang et al., 2003). This anisotropic ice may be an order of magnitude "softer" against deformation in certain directions than ice with random fabric, and has an important influence on the age of ice in the lower $1 / 3$ of the ice thickness (Martín and Gudmundsson, 2012; Seddik et al., 2011). Deep ice cores from sites such as 
Vostok and NorthGRIP in Greenland, which are not located on a true dome geometry, exhibit a girdle-type fabric pattern (Lipenkov et al., 1989; Montagnat et al., 2014), whereas deep ice in Dome $\mathrm{C}$ and the Greenland summit GRIP ice core exhibit single maximum; that is, the $c$ axes are concentrated along the vertical direction (Thorsteinsson et al., 1997; Wang et al., 2003). At Dome F, which is perhaps the closest analogue to the Dome A region, a single maximum fabric dominated the bottom $1 / 3$ of the ice core (Seddik et al., 2011).

\section{Data and model}

The open source - finite element method package Elmer/Ice (Gagliardini et al., 2013; http://elmerice.elmerfem.org) that has been used for the ice dynamical part of our simulations solves the complete three-dimensional, thermomechanically coupled ice dynamics equations without any assumptions on the shallowness of the flow, a so-called "full-Stokes" model (e.g. Zwinger and Moore, 2009; Seddik et al., 2011). The Stokes equation denotes the balance for linear momentum, which in case of ice sheet flow simply is given by the vanishing sum of net stress forces and weight due to gravity $\rho g$ :

$\rho \nabla \cdot \boldsymbol{\sigma}+\rho \boldsymbol{g}=0$

The Cauchy stress tensor $\sigma$ is usually split into two parts $\boldsymbol{\sigma}=\boldsymbol{\tau}-p \mathbf{I}$, with $p$ denoting pressure ( $\mathbf{I}$ is the identity matrix) and $\tau$ representing the deviatoric stress tensor that is expressed in terms of the strain rate tensor $\dot{\boldsymbol{\varepsilon}}=\frac{1}{2}\left(\nabla \boldsymbol{u}+\nabla \boldsymbol{u}^{T}\right)$. The function that relates those two tensors is the effective viscosity, which for ice as an isotropic material takes the form of a general Norton-Hoff fluid:

$\eta_{0}=\frac{1}{2} A\left(T^{\prime}\right)^{-\frac{1}{n}}\left(\frac{1}{2} \operatorname{tr}(\dot{\boldsymbol{\varepsilon}})^{2}\right)^{-\frac{1-n}{2 n}}$,

where $A\left(T^{\prime}\right)$ is the Arrhenius factor depending on the temperature relative to pressure melting, $T^{\prime}$, and the exponent in Glen's flow law takes the value $n=3$. This isotropic relation is extended to account for anisotropy by introducing a tensor relation between the strain rate tensor and the deviatoric stress tensor (e.g. Gillet-Chaulet et al., 2006; Martín and Gudmundsson, 2012) that employs the ice fabric orientation tensor and the ratios of the shear viscosity parallel to the basal plane to that in the basal plane, and the viscosity in compression or traction along the $c$ axis to that in the basal plane. If the local temperature is at the pressure melting point, then a basal melting rate is calculated (Seddik et al., 2011), and as surface velocities are very low, basal sliding was ignored. This will be incorrect wherever ice at the pressure melting point rests on a sloping bed. However we do not think that there is presently a realistic way of including sliding given the lack of information on the basal properties in the model domain. If we were to consider using a sliding

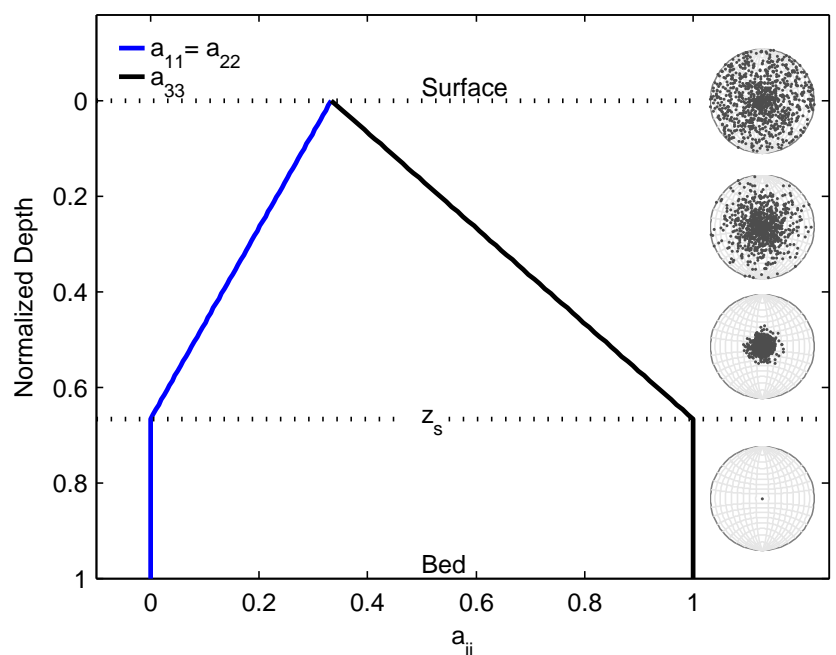

Figure 2. Prescribed fabric distribution with depth. The fabric is represented by the three eigenvalues of the orientation tensor (e.g. Martín and Gudmundsson, 2012), with isotropic ice having $a_{11}=a_{22}=a_{33}=1 / 3$ and single maximum with $a_{11}=a_{22}=0$ and $a_{33}=1$. We also use depth-varying (girdle) fabrics where eigenvalues vary linearly from the surface, where ice is isotropic, to a particular normalized depth $z_{\mathrm{s}}=\{1 / 32 / 3\}$, where we assume single-maximum fabric. The Schmidt diagram of the crystal orientations at selected depths is shown on the right side of the figure with the upper plot being isotropic, the lower being single maximum and middle ones being girdle fabrics.

law, we would necessarily introduce new parameters, creating a larger dimensional space to be explored. The effect of basal sliding would be a local increase in horizontal flow and vertical velocity (due to friction heat). We can ignore the increase in horizontal flow and argue that the increase in vertical velocity is small in areas with low horizontal velocity and basal shear, and also small compared with the uncertainty in geothermal flux, which we explore.

A network of extensive ice penetrating radar (Cui et al., 2010; Sun et al., 2009; Bell et al., 2011; Tang et al., 2011), topographic (Zhang et al., 2007), and shallow ice core surveys (Jiang et al., 2012; Xiao et al., 2008) in the region surrounding the Kunlun field station provides input data for the model and helps to constrain the model results to meet observations. A $30 \times 30 \mathrm{~km}^{2}$ domain with an unstructured mesh of about $300 \mathrm{~m}$ horizontal resolution was embedded within a coarse $(3 \mathrm{~km}) 70 \times 70 \mathrm{~km}^{2}$ unstructured mesh domain centred at Kunlun station (Fig. 1); this arrangement makes optimal use of the various airborne and ground-based radar data. At the lateral domain boundaries (about 10 times the ice thickness away from the drill site), a zero-flux (or adiabatic) condition is applied to the temperature field while the velocity field was calculated using the hydrostatic approximation prescribing the vertical conservation of linear momentum (e.g. Greve and Blatter, 2009). Hence results will become inaccurate towards the domain boundaries. Nevertheless, the distance to 
Table 1. Boundary conditions for the simulations.

\begin{tabular}{|c|c|c|c|}
\hline & Kinematic BC & Dynamic BC & Thermodynamic BC \\
\hline Free surface & Fixed geometry & $\begin{array}{l}\text { Vanishing Cauchy } \\
\text { stress vector (i.e. no } \\
\text { atmospheric force): } \\
\boldsymbol{\sigma} \cdot \boldsymbol{n}=0\end{array}$ & $\begin{array}{l}\text { Given surface temperature: either fixed } \\
T=-58.5^{\circ} \mathrm{C} \text { or }-68.5^{\circ} \mathrm{C} \text {. For the transient } \\
\text { run } T=-58.5^{\circ} \mathrm{C} \text { between } 0 \text { and } 11.5 \mathrm{kyr} \mathrm{BP} \\
\text { and from } 115 \text { to } 130 \mathrm{kyr} \mathrm{BP} \text {; and } T=-68.5 \\
\text { from } 11.5 \text { to } 115 \mathrm{kyr} \mathrm{BP} \text { with a } 200 \text {-year } \\
\text { time step spun up from steady-state glacial } \\
\text { conditions. }\end{array}$ \\
\hline Bedrock & $\begin{array}{l}\text { Fixed geometry and } \\
\text { zero tangential veloc- } \\
\text { ity; normal velocity } \\
\text { determined by melting }\end{array}$ & None & $\begin{array}{l}\text { Prescribed normal component of heat flux } \\
\text { (i.e. normal gradient of temperature): } 50 \text { or } \\
60 \mathrm{~mW} \mathrm{~m}^{-2} \text {. Surface heat sink due to latent } \\
\text { heat from melting }\end{array}$ \\
\hline Sideward & Fixed geometry & $\begin{array}{l}\text { Hydrostatic normal } \\
\text { component of external } \\
\text { force }\end{array}$ & $\begin{array}{l}\text { Adiabatic boundary (i.e. vanishing normal com- } \\
\text { ponent of heat flux) }\end{array}$ \\
\hline
\end{tabular}

the inner domain should ensure that there is no influence on results around Kunlun station (Seddik et al., 2011). The domain was divided into 20 vertical layers with the lower 6 having logarithmic spacing with the bottommost layer representing $0.3125 \%$ of ice thickness. Geothermal heat flux is the most significant unknown boundary condition in determining the basal age of ice across Antarctica (e.g. Van Liefferinge and Pattyn, 2013). Van Liefferinge and Pattyn (2013) produce a map of the broad-scale heat flux and its uncertainty based on three different estimates, which gives about $50 \pm 25 \mathrm{~mW} \mathrm{~m}^{-2}$ in the Dome A region. The presence of both basal melt and freezing conditions in the Dome A region (Bell et al., 2011) helps limit geothermal heat flux values. Experiments show that below $45 \mathrm{~mW} \mathrm{~m}^{-2}$ very little basal melt occurs over the domain, while above $60 \mathrm{~mW} \mathrm{~m}^{-2}$ basal melt occurs even below ice $2400 \mathrm{~m}$ thick suggesting more widespread melt than Bell et al. (2011) observed. Hence we make our simulations with either 50 or $60 \mathrm{~mW} \mathrm{~m}^{-2}$ heat fluxes across the domain.

The present-day temperature of $-58.5^{\circ} \mathrm{C}$ is likely about $10^{\circ} \mathrm{C}$ warmer than that during the Last Glacial Maximum (LGM) over the East Antarctic plateau (Ritz et al., 2001), and accumulation rates during the LGM were perhaps half that of present day (e.g. Watanabe et al. (2003) found about $45 \%$ for much of the glacial at Dome F). We examine the impact of changing surface temperatures using both a transient simulation through the last glacial cycle (starting from $130 \mathrm{kyr}$ BP), forced by a temporal varying surface temperature (but on the fixed present-day geometry), and steady-state simulations using both glacial and modern surface temperatures. As the surface is almost flat, we assumed the whole domain was at the same surface temperature. All boundary conditions applied to the domain boundaries are depicted in Table 1.

The elevation of the Antarctic ice sheet has varied over glacial timescales as a result of changes in both surface accu- mulation rate and the grounding line at the ice margin. The effects of accumulation rate increase and grounding line retreat following the LGM would tend to cancel out, and modelling suggests that elevation changes of less than about $50 \mathrm{~m}$ occurred at Dome A (Saito and Abe-Ouchi, 2010; Ritz et al., 2001). Hence we keep geometry fixed in all (even transient) simulations. This assumption is, of course, unrealistic, but rather practical given the exploratory nature of this work. The fixed geometry means that the surface mass balance, $a_{\mathrm{s}}$, no longer is a parameter, but it is rather determined by the solution of the stationary kinematic boundary condition

$a_{\mathrm{s}}=u_{\mathrm{s}} \frac{\partial z_{\mathrm{s}}}{\partial x}+v_{\mathrm{s}} \frac{\partial z_{\mathrm{s}}}{\partial y}-w_{\mathrm{s}}$,

where $\left(u_{\mathrm{s}}, v_{\mathrm{s}}, w_{\mathrm{s}}\right)^{T}$ denotes the velocity vector at the free surface, and $\left(-\frac{\partial z_{\mathrm{s}}}{\partial x},-\frac{\partial z_{\mathrm{s}}}{\partial y}, 1\right)^{T}$ is the gradient of the free surface. Whereas the first vector is obtained from the ice flow solution, the latter is derived from the fixed present-day geometry. We can then use discrepancies between derived accumulation rates and the measured values as an evaluation criterion for the variable parameter space, as discussed in Sect. 4.

Since we do not know the actual ice fabric at Kunlun, we illustrate a range of possibilities by prescribing three alternative, time-invariant scenarios in the central $30 \times 30 \mathrm{~km}^{2}$ area: isotropic, single maximum, and linear development of a "solid-cone" fabric where all the $c$ axes are uniformly and randomly distributed within a cone (or horizontal "girdle"), whose half angle we contract smoothly from $90^{\circ}$ (equivalent to isotropic) at the ice surface to zero (single maximum) at $1 / 3$ or $2 / 3$ depth and thence to the ice base (Fig. 2). Fabric variations in the Dome F, GRIP and EPICA Dome $\mathrm{C}$ ice cores showed isotropic ice in the upper parts with an evolution to a single maximum, which at Dome F persisted over most of the bottom $1 / 3$ of the ice core (Seddik et al., 2011). Therefore the most likely dating for the upper parts of the ice column 

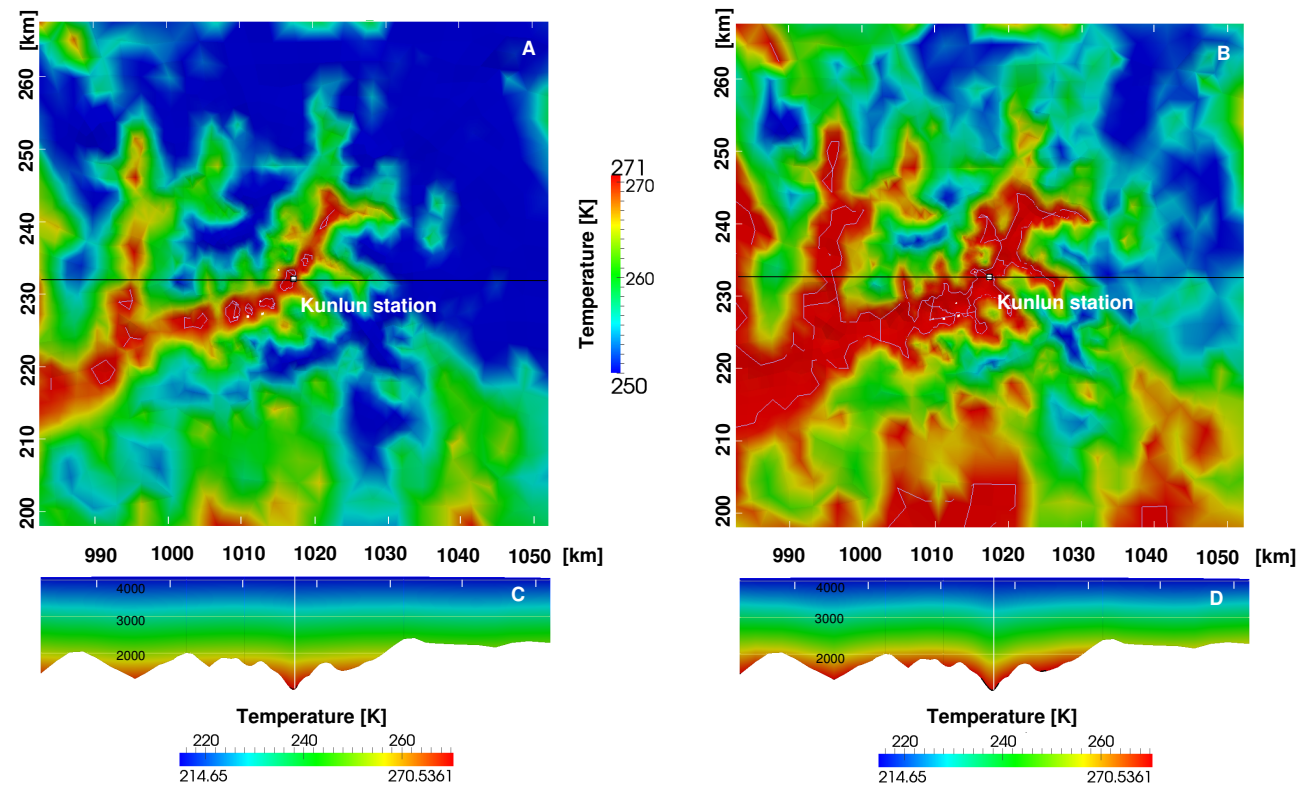

Figure 3. Basal and vertical temperature distribution for $50 \mathrm{~mW} \mathrm{~m}^{-2}$ (A and $\mathbf{C}$ ) and $60 \mathrm{~mW} \mathrm{~m}^{-2}$ (B and $\left.\mathbf{D}\right)$ geothermal heat flux over the $70 \times 70 \mathrm{~km}^{2}$ domain for the solid-cone or horizontal girdle with transition depth, $z_{\mathrm{s}}=1 / 3$ fabric simulations. The vertical temperature distribution is shown in a transect from west to east across the domain cutting through the Kunlun drill site at the centre (black line in upper picture). The vertical coordinate is stretched by a factor of 5 . The bedrock areas at pressure-melting point are surrounded by a white contour in plan view pictures and with black bedrock in the vertical cross sections. Note the different colour bar scales for the plan and vertical cross sections.

comes from assuming a thinning rate from an isotropic fabric layer while those deeper would likely follow the thinning rates from the single maximum fabric. Hence we expect that, of the three alternatives, the girdle fabric would provide the most likely description of ice fabric for the whole core.

We compute steady-state and transient solutions with fixed present-day geometry. Firstly, we obtain a steady-state solution for a linear (Newtonian fluid) rheology, in order to avoid the singularity of Glen's flow law at zero-shear initial condition. Secondly, restarting with this result, we compute for the isotropic steady-state run with non-linear (Glen's flow law) rheology. Thirdly, we take the isotropic steadystate solution as the initial guess from which we start to compute the anisotropic case. To calculate the age of the ice, $A$, would require velocity profiles over the full history of the ice sheet. Instead we solve the advection equation using a semi-Lagrangian method (Martín and Gudmundsson, 2012) and using the previously obtained steady-state velocity profile, $\mathbf{u}$, and a time non-varying geometry as the evolution of flow over glacial cycles is unknown. Hence, we cannot compute the age for the single glacial cycle transient simulation we perform. In our simulations we impose a $1.5 \mathrm{Myr}$ limit to the age solver. In areas with no basal melt, no steady-state solution of the age equation exists; in areas of basal melting, a steady-state solution may exist locally. We have a mixture of these cases. Clearly we will not get the actual age of the oldest ice, but we will see where the ice is younger than the maximum run time of the model.

\section{Results}

\subsection{Basal melt and temperatures}

Basal melting rate is sensitive to surface accumulation rate and temperature, ice thickness and geothermal heat flux. As described in Sect. 2, we prescribe fixed geometry which implicitly determines accumulation rates. For $50 \mathrm{~mW} \mathrm{~m}^{-2}$ heat flux, only a small fraction of the basal ice in the $30 \times 30 \mathrm{~km}^{2}$ domain is at the pressure melting point, including Kunlun station drill site (Fig. 3). Basal melting is considerably stronger for $60 \mathrm{~mW} \mathrm{~m}^{-2}$ heat flux (Fig. 3), and the spatial extent of melting is also greatly increased despite the steep topography.

\subsection{Vertical velocity and age profile}

The geothermal heat flux does not greatly affect internal temperatures in the ice sheet (Fig. 3), but it impacts vertical velocity in the ice sheet (Fig. 4) when basal melting occurs. This is particularly important in determining the age profile of the ice (Fig. 4). Simulations with the same fabric but higher geothermal heat flux or warmer surface temperatures produce larger vertical velocities than cooler ones as the ice tends to be softer and has more melt. However, the order of the profiles in Fig. 4 by fabric is not entirely intuitive: while generally isotropic ice has higher vertical velocity than girdle and single maximum fabrics, the curves often cross each 


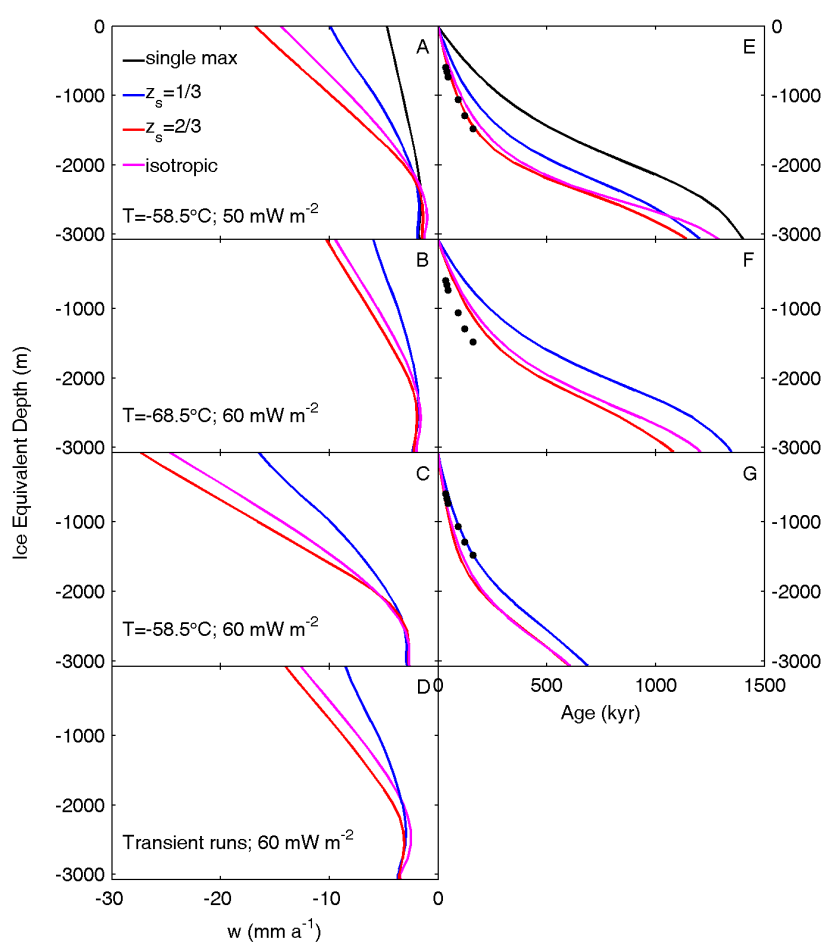

Figure 4. (A-D) Vertical velocity, $w$, as a function of depth from the surface to bedrock for different fabrics, surface temperature and geothermal heat flux at Kunlun station. (A-C) are steady-state simulations using fabric as in the key of (A). Surface temperatures and geothermal heat fluxes and surface temperatures are labelled on the panels. (D) is for the transient simulations with time-varying surface temperature (Table 1) from $130 \mathrm{kyr}$ BP. (E-G) Age-depth profile at Kunlun station corresponding to the simulations in the left column. The black points denote the age-depth data from dated radar internal reflection horizons tracked from the Vostok ice core site, using a $46 \mathrm{~m}$ firn correction subtracted from the radar depths to convert to the ice-equivalent model scale. No age calculation is possible for the short transient runs, but the expected ages may be judged by relation to the steady-state $w$ simulations.

other at depth. Presumably this is because of the complexity of the bedrock resulting in three-dimensional ice deformation and flow being captured by the full-Stokes model. This behaviour is far from the simple flow pattern that may be imagined from the smooth dome-like surface topography or simulated using over-simplified flow models. The modelled age profile can be compared with ages in the upper part of the ice sheet from dated radar internal reflection horizons tracked from the Vostok ice core site. The dated radar isochrones do not extend further backwards than $160 \mathrm{kyr} \mathrm{BP}$, or about the upper $1 / 3$ of the ice depth at Kunlun station.

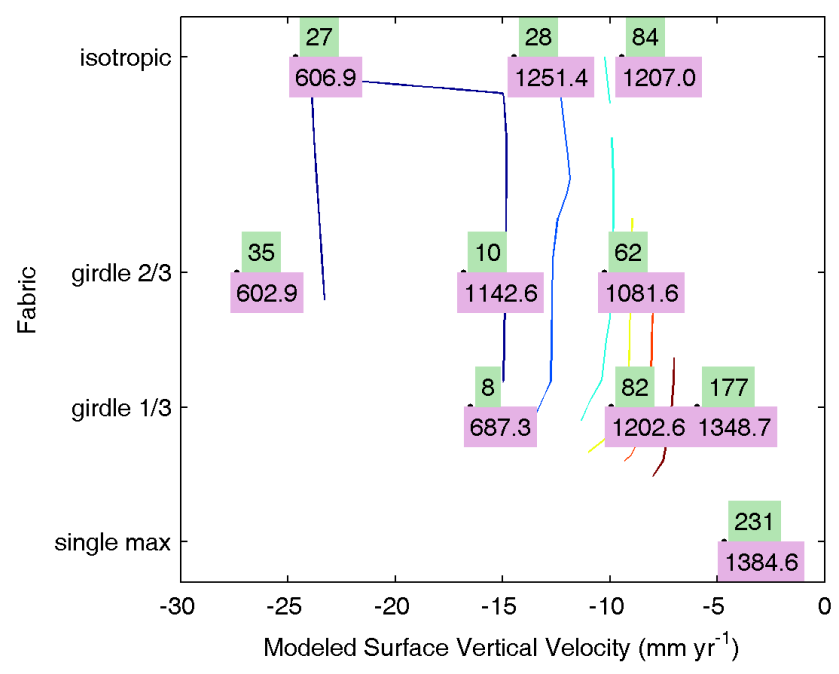

Figure 5. Relationship between vertical surface velocity $w_{\mathrm{s}}$ and fabric shows that there is a minimum mismatch of age (contoured root mean square, in kyr; green boxed values) between the observed radar isochrones and those modelled for various fabrics. Numbers in magenta boxes are the basal ages for those simulations. The mismatch in ages is least for $20>w_{\mathrm{s}}>15 \mathrm{~mm} \mathrm{yr}^{-1}$, whereas simplistic expectations assuming fixed geometry and accumulation rate variability over a glacial cycle would suggest a long-term steady-state surface mass balance and $w_{\mathrm{s}}$ of about $14 \mathrm{~mm} \mathrm{yr}^{-1}$.

\section{Discussion}

The age of the ice depends on the vertical velocity profile in the ice, which depends on the basal melt rate, governed entirely in our model by the geothermal heat flux, surface temperature and the ice fabric (see Fig. 4). The normal velocity at the surface, $w_{\mathrm{s}}$, in all simulations is the accumulation rate since we specify a fixed geometry in the simulations. All the steady-state simulations with glacial surface temperature produce $w_{\mathrm{s}}$ notably too low even with a geothermal heat flux of $60 \mathrm{~mW} \mathrm{~m}^{-2}$. Present-day accumulation rates are about $25 \mathrm{~mm}$ ice equivalent $\mathrm{yr}^{-1}$, and those in the glacial periods about half that. Hence reasonable simulations should produce $w_{\mathrm{s}}$ of about $14 \mathrm{~mm}$ ice equivalent $\mathrm{yr}^{-1}$. The discrepancies in the modelled ages of the radar isochrones are smaller when the simulation produces $w_{\mathrm{s}}$ between 15 and $20 \mathrm{~mm}$ equivalent $\mathrm{yr}^{-1}$ (Fig. 5). The transient simulations, despite being $>80 \%$ of the simulation time at glacial temperatures, give plausible thinning rates for isotropic and $2 / 3$ transition depths girdle fabrics, while the $1 / 3$ girdle transition case gives notably too low values of $w_{\mathrm{s}}$. Although surface temperatures play an important role in values of $w_{\mathrm{s}}$, the warm interglacials seem to play a key role in changing its glacial cycle average value. The rms errors in Fig. 5 are larger for both isotropic and single maximum fabrics than for the depth evolving girdle cases, as we may expect from observations on ice cores. The two best fits are from steadystate simulations with present-day surface temperature, using 


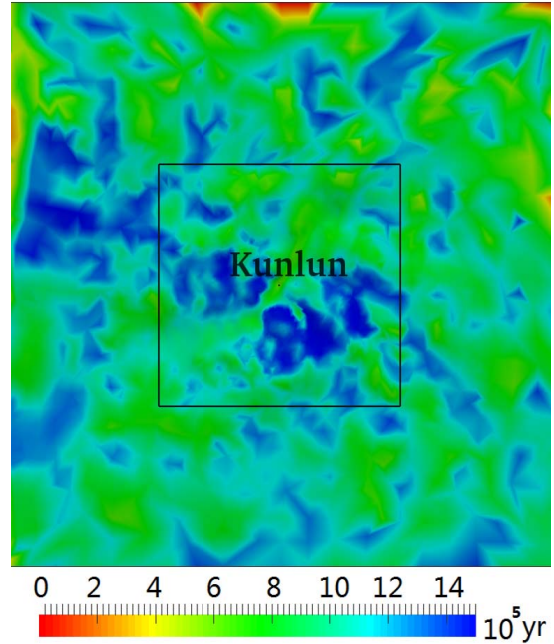

Figure 6. Age of the ice at $95 \%$ depth in the $70 \times 70 \mathrm{~km}^{2}$ domain (central $30 \times 30 \mathrm{~km}^{2}$ region is boxed) using girdle fabric with $1 / 3$ transition depth, $60 \mathrm{~mW} \mathrm{~m}^{-2}$ heat flux and surface temperature of $-58.5^{\circ} \mathrm{C}$. The parts with no basal melt are limited to an age of $1.5 \mathrm{Myr}$.

girdle fabric $z_{\mathrm{s}}=1 / 3$ and $60 \mathrm{~mW} \mathrm{~m}^{-2}$ heat flux (blue line in Fig. $4 \mathrm{~g}$ ), and using girdle fabric $z_{\mathrm{s}}=2 / 3$ and $50 \mathrm{~mW} \mathrm{~m}^{-2}$ heat flux (red line in Fig. 4f). However, as isochrones are only available for the upper $1 / 3$ of the ice sheet thickness, they cannot constrain the age near the bed as different, but reasonable combinations of fabrics, geothermal heat flux, and surface temperature can produce essentially identical behaviour in the upper $1 / 3$ of the ice sheet that diverges dramatically in the deeper parts (Fig. 4). Hence, with the observations available now, we cannot constrain the age of the basal ice well.

The large sensitivities and discrepancies from radar isochrone dates produced by different simulations question the assumptions made in the model, particularly the fixed surface geometry (imposing constant accumulation rates) and spatially unvarying heat flux across the domain. We suggest that Dome A is a dynamic region where basal conditions are sensitive to small changes in surface forcing, such as thickness changes of tens of metres, which can switch bedrock locally from melting to freeze-on, driving changes in hydrology and latent heat distribution, and perhaps the unusual basal accretion noted in the radar surveys (Bell et al., 2011). Long period transient simulations with varying geometry and accumulation rate to study this can be done if sufficient computing power is available.

Another open question is the lateral distribution of fabric, induced by the - in comparison to other large ice-core drilling sites - uniquely steep and rough bedrock topography of the Gamburtsev mountain range. The kinematic constraints imposed by the bedrock (including local sliding at temperate base) may lead to locally strong variations of vertical shearing and, in consequence, of the fabric perhaps with even a dynamic feedback on the flow.
As the drill site is located at one of the deepest parts of the steep valley under Kunlun station, much older ice may be expected within a few hundred metres (Fig. 6). The general layout of valley troughs in Fig. 1 is suggested in Fig. 6 as the troughs tend to exhibit basal melting. However, there is clearly not a perfect correlation with ice thickness even though surface slope is gentle and geothermal heat flux is constant. Hence, this provides confirmation of the finding deduced by the results in Fig. 4 - that the three-dimensional flow is very relevant to the age distribution. The full-Stokes flow model we used accommodates the Raymond effect. However, we see no characteristic upwarping of isochrones, probably because the complex bedrock topography diffuses the effect, and more importantly, the presence of melting will damp the Raymond effect. Exploring such phenomena could be done by off-nadir drilling in order to examine lateral fabric distributions. We expect a significant improvement of the model, once the input of a measured fabric distribution has been incorporated. It is therefore possible that the Kunlun site would provide both a highly resolved record of the past 6-700 000 years from vertical drilling, and a longer but lower resolution record from off-nadir drilling. Indeed exploration of the basal valley features may well also lead to knowledge of the sub-basal hydrology and accretion processes observed by radar surveys of the area.

Acknowledgements. Work was supported by China's National Key Science Program for Global Change Research (2012CB957702, 2010CB950504, 2010CB951401 and 2012CB957704) and NSFC Q72 41076125, the National High-tech R\&D Program of China (2011AA040202), and the Chinese Polar Environmental Comprehensive Investigation and Assessment Programs (CHINARE-02-02). We thank N. B. Karlsson for a thoughtful and useful review.

Edited by: F. Pattyn

\section{References}

Bell, R. E., Ferraccioli, F., Creyts, T. T., Braaten, D., Corr, H., Das, I., Damaske, D., Frearson, N., Jordan, T., Rose, K., Studinger, M., and Wolovick, M.: Widespread Persistent Thickening of the East Antarctic Ice Sheet by Freezing from the Base, Science, 331, 1592-1595, doi:10.1126/science.1200109, 2011.

Cui, X., Sun, B., Tian, G., Tang, X., Zhang, X., Jiang, Y., Guo, J., and $\mathrm{Li}, \mathrm{X}$.: Ice radar investigation at Dome A, East Antarctica: Ice thickness and subglacial topography, Chinese Sci. Bull., 55 , 425-431, doi:10.1007/s11434-009-0546-z, 2010.

DeConto, R. M. and Pollard, D.: Rapid Cenozoic glaciation of Antarctica induced by declining atmospheric $\mathrm{CO}_{2}$, Nature, 421, 245-249, 2003.

Durand, G., Svensson, A., Persson, A., Gagliardini, O., GilletChaulet, F., Sjolte, J., Montagnat, M., and Dahl-Jensen, D.: Evolution of the texture along the EPICA Dome C ice core, Supp. Issue Low Temperature Science, 68, 91-106, 2009. 
Fujita, S., Maeno, H., Uratsuka, S., Furukawa, T., Mae, S., Fujii, Y., and Watanabe, O.: Nature of radio echo layering in the Antarctic ice sheet detected by a two-frequency experiment, J. Geophys. Res., 104, 13013-13024, doi:10.1029/1999JB900034, 1999.

Gagliardini, O., Zwinger, T., Gillet-Chaulet, F., Durand, G., Favier, L., de Fleurian, B., Greve, R., Malinen, M., Martín, C., Råback, P., Ruokolainen, J., Sacchettini, M., Schäfer, M., Seddik, H., and Thies, J.: Capabilities and performance of Elmer/Ice, a newgeneration ice sheet model, Geosci. Model Dev., 6, 1299-1318, doi:10.5194/gmd-6-1299-2013, 2013.

Gillet-Chaulet, F., Gagliardini, O., Meyssonnier, J., Zwinger, T., and Ruokolainen, J.: Flow-induced anisotropy in polar ice and related ice-sheet flow modeling, J. Non-Newton. Fluid, 134, 33 43, 2006.

Greve, R. and Blatter, H.: Dynamics of Ice Sheets and Glaciers, Springer-Verlag, Berlin Heidelberg, 287 pp., 2009

Hou, S., Li, Y., Xiao, C., and Ren, J.: Recent accumulation rate at Dome A, Antarctic, Chinese Sci. Bull., 52, 428-431, 2007.

Jiang, S., Cole-Dai, J., Li, Y., Ferris, D.G., Ma, H., An, C., Shi, G., and Sun B.: A detailed 2840 year record of explosive volcanism in a shallow ice core from Dome A, East Antarctica, J. Glaciol., 58, 65-75, 2012.

Lipenkov, V. Y., Barkov, N. I., Duval, P., and Pimienta, P.: Crystalline texture of the $2083 \mathrm{~m}$ ice core at Vostock Station, Antarctica, J. Glaciol. 35, 392-398, 1989.

Martín, C. and Gudmundsson, G. H.: Effects of nonlinear rheology, temperature and anisotropy on the relationship between age and depth at ice divides, The Cryosphere, 6, 1221-1229, doi:10.5194/tc-6-1221-2012, 2012.

Montagnat, M., Azuma, N., Dahl-Jensen, D., Eichler, J., Fujita, S., Gillet-Chaulet, F., Kipfstuhl, S., Samyn, D., Svensson, A., and Weikusat, I.: Fabric measurement along the NEEM ice core, Greenland, and comparison with GRIP and NGRIP ice cores, The Cryosphere Discuss., 8, 307-335, doi:10.5194/tcd-8-3072014, 2014.

Ritz, C., Rommelaere, V., and Dumas, C.: Modeling the evolution of Antarctic ice sheet over the last 420,000 years: implications for altitude changes in the Vostok region, J. Geophys. Res., 106, 31943-31964, 2001.

Saito, F. and Abe-Ouchi, A.: Modelled response of the volume and thickness of the Antarctic ice sheet to the advance of the grounded area, Ann. Glaciol., 51, 41-48, 2010.
Seddik, H., Greve, R., Zwinger, T., and Placidi, L.: A full Stokes ice flow model for the vicinity of Dome Fuji, Antarctica, with induced anisotropy and fabric evolution, The Cryosphere, 5, 495508, doi:10.5194/tc-5-495-2011, 2011.

Severinghaus, J.: Searching for the oldest ice, Eos Trans. AGU, 91, 357-358, 2010.

Shoji, H. and Langway, C.: The ice flow velocity profile for Dye-3, Greenland, Geophys. Res. Lett., 12, 797-800, doi:10.1029/GL012i012p00797, 1985.

Sun, B., Siegert, M. J., Mudd, S. M., Sugden, D., Fujita, S., Cui, X., Jiang, Y., Tang, X., and Li, Y.: The Gamburtsev mountains and the origin and early evolution of the Antarctic ice sheet, Nature, 459, 690-693, doi:10.1038/nature08024, 2009.

Tang, X., Sun, B., Zhang, Z., Zhang, X., Cui, X., and Li, X.: Structure of the internal isochronous layers at Dome A, East Antarctica, Sci China Earth Sci., 54, 445-450, doi:10.1007/s11430010-4065-1, 2011.

Thorsteinsson, T., Kipfstuhl, J., and Miller, H.: Textures and fabrics in the GRIP ice core, J. Geophys. Res., 102, 26583-26600, 1997.

Van Liefferinge, B. and Pattyn, F.: Using ice-flow models to evaluate potential sites of million year-old ice in Antarctica, Clim. Past, 9, 2335-2345, doi:10.5194/cp-9-2335-2013, 2013.

Wang, Y., Kipfstuhl, J., Azuma, N., Thorsteinsson, T., and Miller, H.: Ice-fabrics study in the upper $1500 \mathrm{~m}$ of the Dome C (East Antarctica) deep ice core, Ann. Glaciol., 37, 97-104, 2003.

Watanabe, O., Shoji, H., Satow, K., Motoyama, H., Fujii, Y., Narita, H., and Aoki, S.: Dating of the Dome Fuji Antarctica deep ice core, Mem. Natl. Inst. Polar Res. Spec. Iss., 57, 25-37, 2003.

Xiao C., Li, Y., Hou, S., Allison, I., Bian, L., and Ren, J.: Preliminary evidence indicating Dome A (Antarctic) satisfying preconditions for drilling the oldest ice core, Chinese Sci. Bull., 53, 102-106, 2008.

Zhang S., Wang, D., Zhou C., and Shen Q.: Surface topography around the summit of Dome A, Antarctica, from real-time kinematic GPS, J. Glaciol., 53, 159-160, doi:10.3189/172756507781833965, 2007.

Zwinger, T. and Moore, J. C.: Diagnostic and prognostic simulations with a full Stokes model accounting for superimposed ice of Midtre Lovénbreen, Svalbard, The Cryosphere, 3, 217-229, doi:10.5194/tc-3-217-2009, 2009. 